\title{
N6-Methyladenosine Modification Changes in the Genome of Paulownia Fortunei Seedlings Infected With Phytoplasma
}

\author{
Pingluo Xu \\ Henan Agricultural University \\ Shunmou Huang \\ Henan Agricultural University \\ Xiaoqiao Zhai \\ Henan Province Academy of Forestry \\ Xiaofan Li \\ Henan Agricultural University \\ Haibo Yang \\ Henan Agricultural University \\ Yabing Cao \\ Henan Agricultural University \\ Guoqiang Fan ( $\sim$ zlxx64@126.com ) \\ Henan Agricultural University
}

\section{Research Article}

Keywords: phytoplasma, Paulownia fortunei, m6A sequencing, witches' broom

Posted Date: January 12th, 2022

DOI: https://doi.org/10.21203/rs.3.rs-1168186/v1

License: @ (7) This work is licensed under a Creative Commons Attribution 4.0 International License. Read Full License 


\section{Abstract}

Background: Phytoplasmas induce diseases in more than 1,000 plant species and cause substantial ecological damage and economic losses, but the specific pathogenesis of phytoplasma has not yet been clarified. $\mathrm{N}^{6}$-methyladenosine sequencing $\left(\mathrm{m}^{6} \mathrm{~A}\right.$-seq) has been applied mainly to model plants and not to woody plants.

Results: In this study, we applied $\mathrm{m}^{6} \mathrm{~A}$-seq to study changes in $\mathrm{m}^{6} \mathrm{~A}$ modification in the Paulownia fortunei genome after phytoplasma infection. We found that the $\mathrm{m}^{6} \mathrm{~A}$ modification level in seedlings infected with the phytoplasma that causes Paulownia witches' broom (PaWB) was slightly higher than the $\mathrm{m}^{6} \mathrm{~A}$ modification level in PaWB-infected seedlings treated with $60 \mathrm{mg} \cdot \mathrm{L}^{-1} \mathrm{methyl}$ methanesulfonate (MMS). MMS has been shown to restore PaWB-infected seedlings to their normal form and no phytoplasma can be detected in MMS-treated PaWB-infected seedlings. RNA sequencing (RNA-seq) and $\mathrm{m}^{6} \mathrm{~A}$-seq were used to analyze the expression of genes with $\mathrm{m}^{6} \mathrm{~A}$ peaks and $\mathrm{m}^{6} \mathrm{~A}$ motifs in genes, respectively. The correlation analysis between the RNA-seq and $\mathrm{m}^{6} \mathrm{~A}$-seq data detected that a total of 315 differentially methylated genes were predicted to be significantly differentially expressed at the transcriptome level. The functions of genes related to PaWB were predicted by functional enrichment analysis, and two genes related to maintenance of the basic mechanism of stem cells in shoot apical meristem were discovered. One of the genes encodes the receptor protein kinase CLV2 (Paulownia_LG2G000076), and the other gene encodes the homeobox transcription factor STM (Paulownia_LG15G000976). The $\mathrm{m}^{6} \mathrm{~A}$ modification levels were higher in PaWB-infected seedlings than they were in MMS-treated seedlings. In addition, genes F-box (Paulownia_LG17G000760) and MSH5 (Paulownia_LG8G001160) had exon skipping and mutually exclusive exon types of alternative splicing in PaWB-infected seedling treated with MMS. RT-PCR verified that the alternative splicing of these two genes was related to $\mathrm{m}^{6} \mathrm{~A}$ modification.

Conclusions: In this study, we applied m6A-seq to determine methylation levels in phytoplasma-infected Paulownia, and combined m6A-seq with transcriptome analysis to screen differentially expressed genes associated with PaWB. Also analyzed the effect of m6A methylation on alternative splicing. In future studies, we plan to verify genes directly related to PaWB and methylation-related enzymes in Paulownia to elucidate the pathogenicity mechanism of PaWB caused by phytoplasma invasion.

\section{Background}

$\mathrm{N}^{6}$-methyladenosine is the most common post-transcriptional modification of mRNA. It is regulated by methyltransferases, demethylases, and $\mathrm{m}^{6} \mathrm{~A}$-binding proteins (Dominissini et al. 2012; Meyer et al. 2012; Schwartz et al. 2013; Luo et al. 2014; Deng et al. 2015). The regulation of $\mathrm{m}^{6} \mathrm{~A}$ modification involves a complex dynamic system that includes processes related to embryonic development, apoptosis, spermatogenesis, and circadian rhythm (Zhong et al. 2008; Jia et al. 2011; Zheng et al. 2013; Liu et al. 2014; Ping et al. 2014; Zhao et al. 2017; Yang et al. 2018). If components of the $\mathrm{m}^{6} \mathrm{~A}$ modification system are defective, diseases or disorders can occur, including tumors, neurological diseases, and delayed embryonic development (Zhong et al. 2008; Liu et al. 2013; Zheng et al. 2013; Ping et al. 2014; Lin et al. 2016; Zhang et al. 2016; Li et al. 2017; Zhao et al. 2017). In addition, $\mathrm{m}^{6} \mathrm{~A}$ is involved in a variety of RNA metabolic processes, including mRNA expression (Dominissini et al. 2012), translation efficiency (Wang et al. 2015), alternative splicing (Liu et al. 2015), and degradation (Wang et al. 2013).

Homologs of some $\mathrm{m}^{6} \mathrm{~A}$-related proteins in Paulownia have been identified in the model plant Arabidopsis thaliana (Zhong et al. 2008). For example, FIP37, a homolog of WTAP in Arabidopsis, is a core component of the methyltransferase complex that mediates methylation of the transcription factors STM and WUS, and influences the development of aboveground organs (Shen et al. 2016). ALKBH10B is an RNA ${ }^{6} \mathrm{~A}$ demethylase that regulates inflorescence transformation in Arabidopsis (Duan et al. 2017). The $\mathrm{m}^{6} \mathrm{~A}$ reader ECT2 recognizes the site of $\mathrm{m}^{6} \mathrm{~A}$ methylation and regulates the morphogenesis of Arabidopsis trichomes (Wei et al. 2018). In tobacco, the RNA demethylase ALKBH5 is associated with tobacco mosaic virus (Li et al. 2018). Until now, ${ }^{6} \mathrm{~A}$ modification has rarely been investigated in woody plants.

Paulownia is an important fast-growing timber and ornamental tree species indigenous to China, but now planted worldwide. PaWB, a plant disease caused by phytoplasma infection, seriously affects the growth and development of Paulownia and even causes death, resulting in serious economic loss and ecological damage. Phytoplasmas are parasitic prokaryotes that have no cell wall and are transmitted by insect vectors such as psyllids, planthoppers (Kosovac et al. 2018), and woodlice. Phytoplasmas are the causal agents of more than 1,000 plant diseases, including Jujube witches' broom, PaWB, and Aster yellow witches' broom, which are

Page 2/19 
extremely harmful to plants (Geng et al. 2015). Advances in biotechnological techniques have made it possible to study posttranscriptional mRNA modifications, especially $\mathrm{m}^{6} \mathrm{~A}$ modifications, which have become the focus of much research. Given the indispensable function of RNA $\mathrm{m}^{6} \mathrm{~A}$ modification in regulating gene expression and the involvement in various bioprocesses, it is reasonable to speculate that PaWB might also be associated with the regulation of $\mathrm{m}^{6} \mathrm{~A}$ modification. Previous studies have shown that phytoplasma-infected Paulownia seedlings treated with $60 \mathrm{mg} \cdot \mathrm{L}^{-1}$ methyl methanesulfonate (MMS) were restored to the normal morphology, and the phytoplasma was no longer detected (Wang et al. 2018). In this study, we used terminal buds collected from untreated PaWB-infected seedlings (PFI) and PaWB-infected seedlings treated with $60 \mathrm{mg} \mathrm{L}^{-1} \mathrm{MMS}(\mathrm{PFIM60})$ for $\mathrm{N}^{6}$ methyladenosine sequencing ( $\left.\mathrm{m}^{6} \mathrm{~A}-\mathrm{seq}\right)$, RNA sequencing (RNA-seq), and transcriptome analysis. We constructed an $\mathrm{m}^{6} \mathrm{~A}$ methylation map of Paulownia and screened for genes involved in the recovery process of PaWB disease by combining m6A-seq with transcriptome analysis. Genes that were found to be alternatively spliced because of $\mathrm{m}^{6} \mathrm{~A}$ modification were analyzed to gain insights into gene expression changes in Paulownia in response to phytoplasma infection. Understanding the changes in $\mathrm{m}^{6} \mathrm{~A}$ modification in the Paulownia genome after phytoplasma infection will lay a solid scientific foundation for discovering the pathogenesis and epigenetic regulation mechanisms associated with PaWB.

\section{Results}

\section{The $\mathrm{m}^{6} \mathrm{~A}$ modification landscape of $\mathrm{P}$. fortunei}

PaWB-infected $P$. fortunei (PFI) seedlings and PFI seedlings treated with $60 \mathrm{mg} \cdot \mathrm{L}^{-1} \mathrm{MMS}$ (PFIM60) were used for $\mathrm{m}^{6} \mathrm{~A}$-seq, RNA-seq (total fragmented RNA as the control for m6A-seq), and transcriptome analysis, with two replicates for each. Heatmap correlation coefficient analysis between the biological replicates confirmed their high repeatability (Figure 1). We obtained 44-56 and 73-83 million reads for the RNA-seq and $\mathrm{m}^{6} \mathrm{~A}$-seq libraries, respectively (Supplementary Materials: Tables S1), and 23-28 and 47-50 million of them uniquely aligned to the $P$. fortunei reference genome (Supplementary Materials: Tables S2). Almost $94 \%$ of the reads that were aligned to the reference genome were locating in exons; the others were located in introns or intergenic regions (Supplementary Materials: Figure S1, Supplementary Materials: Tables S3).

We constructed a $\mathrm{m}^{6} \mathrm{~A}$ methylation map of $P$. fortunei that shows the distribution of $\mathrm{m}^{6} \mathrm{~A}$ on the chromosomes, and the distribution of the PFI and PFIM60 $\mathrm{m}^{6} \mathrm{~A}$ peak positions on the chromosomes (Figure 2). The number of $\mathrm{m}^{6} \mathrm{~A}$-modified genes on the chromosomes ranged from 472 to 1,014; chromosome $9(1,014)$ and chromosome $2(1,002)$ had more modified genes than the other chromosomes. The highest number of $\mathrm{m}^{6} \mathrm{~A}$ peaks $(1,506)$ was on chromosome 2 and the lowest number $(702)$ was on chromosome 14 . The numbers of methylated genes and peaks on the chromosomes were similar in PFI and PFIM60.

We obtained 6,606 high-confidence $\mathrm{m}^{6} \mathrm{~A}$ peaks located in 13,837 and 13,505 genes in PFI and PFIM60, respectively, using ChIPseeker; 12,554 of the genes were common to both samples (Supplementary Materials: Tables S4). Notably, there was greater enrichment of peaks at the transcription start and stop sites of genes in both samples (Figure 3a), suggesting $\mathrm{m}^{6} \mathrm{~A}$ modification may play a key role in regulating mRNA degradation and microRNA processing in Paulownia. We compared and analyzed the differences in the observed $\mathrm{m}^{6} \mathrm{~A}$ peaks between PFI and PFIM60. The results showed there were 306 genes with reduced $\mathrm{m}^{6} \mathrm{~A}$ methylation in PFIM60 compared with their $\mathrm{m}^{6} \mathrm{~A}$ methylation in PFI; $36.59 \%$ of them were located in $3^{\prime}$ UTRs, $17.41 \%$ were in $5^{\prime}$ UTRs, $21.58 \%$ were in first exons, and $24.15 \%$ were in other exons. This distribution is consistent with the $\mathrm{m}^{6} \mathrm{~A}$ enrichment of all the genes in the $P$. fortunei genome (Figure $3 b)$.

\section{Differential modified genes between PFI and PFIM60}

To determine the sequence specificity of the hypermethylated $\mathrm{m}^{6} \mathrm{~A}$ peaks, we used HOMER for motif prediction based on the difference peak analysis, and compared the predicted motif to the microRNA sequences in miRBase $\left(1 \mathrm{e}^{-20}<\mathrm{p}<1 \mathrm{e}^{-10}\right)$. A total of 10 highly enriched motif sequences were identified. Among them, the motif RRACH $(R=A / G, H=A / C / U)$, which was identified in Paulownia, has not yet been confirmed in mammals and yeast. The most significantly enriched sequence was UUGUUUUGUACU (Figure 4), which is similar to the UGUAYY $(\mathrm{Y}=\mathrm{C} / \mathrm{U})$ motif that is specific to $\mathrm{m}^{6} \mathrm{~A}$ modifications in tomato, rice, corn, and other plants, indicating that the prediction results have a high degree of confidence. These motif sequences are recognized and bound by $\mathrm{m} 6 \mathrm{~A}-$ related enzymes, which in turn affect gene expression. 
Kyoto Encyclopedia of Genes and Genomes (KEGG) pathway enrichment analysis was performed on the peak-related genes with weakened $\mathrm{m}^{6} \mathrm{~A}$ methylation modification detected in the PFIM60 samples. The results showed that the auxin biosynthesis, hormone signal transduction, and MAPK signal pathways were some of the most enriched pathways (Figure 5; Supplementary Materials: Tables S5). The auxin biosynthesis pathway involves three genes, Paulownia_LG2G000124, Paulownia_LG2G000125, and Paulownia_LG2G000128. The plant hormone (auxin, abscisic acid, and ethylene) signal transduction pathways involve eight genes, Paulownia_LG11G000159, Paulownia_LG12G000675, Paulownia_LG17G000489, Paulownia_LG17G000559, Paulownia_LG2G001457, Paulownia_LG4G000193 and Paulownia_LG4G000193000451. The MAPK signaling pathway involves six genes, Paulownia_LG10G000799, Paulownia_LG11G000159, Paulownia_LG17G000559, Paulownia_LG2G001457, Paulownia_LG4G000451, and Paulownia_LG9G000737.

\section{Extent of $\mathrm{m}^{6} \mathrm{~A}$ methylation versus gene transcript levels in PFI and PFIM60}

First, the transcription levels of the mRNAs in the PFI and PFIM60 libraries were analyzed by calculating the FPKM (FPKM=[total exon fragments/mapped reads (millions) xexon length (kb)]). Differentially expressed mRNAs (DEGs) were identified using the edgeR package in $\mathrm{R}$ ( $\log 2$ (fold change) $>1$ or $<-1$, and $p$ value $<0.05$ ). A total of 5,899 DEGs were detected between the PFI and PFIM60 libraries; 3,130 were up-regulated and 2,769 were down-regulated in PFIM60. Gene ontology (GO) enrichment analysis showed that the DEGs were involved mainly in membrane, cell wall, transcriptional regulation using DNA as a template, secondary metabolite biosynthetic process, DNA binding transcription factor activity, and oxidoreductase activity (Figure 6a). The KEGG pathway enrichment analysis showed that the DEGs were involved mainly in plant circadian rhythm, phenylpropanoid biosynthesis, flavonoid biosynthesis, and glycerolipid metabolism pathways (Figure 6b).

To examine the extent of $\mathrm{m}^{6} \mathrm{~A}$ methylation versus gene transcript levels in the PFI and PFIM60 samples, we correlated the $\mathrm{m}^{6} \mathrm{~A}$-seq data with the transcriptome sequences. In the transcriptome, differences in transcript abundance were categorized as up- and downregulation, whereas in the $\mathrm{m}^{6} \mathrm{~A}$-seq data changes in peak abundance indicated the $\mathrm{m}^{6} \mathrm{~A}$ methylation levels of up-regulated genes. A total of 315 differentially methylated genes were predicted to be significantly differentially expressed at the transcriptome level. Four types of relationships between the $\mathrm{m}^{6} \mathrm{~A}$ methylation levels and gene expression were identified: 1) $\mathrm{m}^{6} \mathrm{~A}$ modification levels and transcription levels both up-regulated (133 genes); 2$) \mathrm{m}^{6} \mathrm{~A}$ modification levels up-regulated and transcription levels down-regulated (58 genes); 3 ) $\mathrm{m}^{6} \mathrm{~A}$ modification levels down-regulated and transcription levels up-regulated (44 genes); and 4) $\mathrm{m}^{6} \mathrm{~A}$ modification levels and transcription levels both down-regulated (80 genes) (Figure 7; Supplemental Data Table S6). The GO enrichment analysis of these differentially methylated genes showed plasma membrane and chloroplast were enriched under the cellular component category, DNA-based template for transcriptional regulation and response to light stimulus were enriched under the biological process category, and DNA-binding transcription factor activity and sequence-specific DNA binding function were enriched under the molecular function category (Figure 8a). The KEGG pathway analysis showed that these differentially methylated genes were involved mainly in signal pathways such as $A B C$ transport, diterpenoid biosynthesis, plant hormone signal transduction, and phenylpropanoid biosynthesis (Figure 8b).

\section{$\mathrm{m}^{6} \mathrm{~A}$ modification affects alternative splicing}

Alternative splicing (AS) is involved in many physiological processes, including responses to abiotic and biotic stresses (Barbazuk et al. 2008). $\mathrm{m}^{6} \mathrm{~A}$ modification can affect AS by promoting the retention of exons at the transcriptional level; therefore, we jointly analyzed $\mathrm{m}^{6} \mathrm{~A}$ modification and AS. In PFIM60, 282 genes had significant exon skipping-type AS differences and 84 genes had significant mutually exclusive exon-type AS differences compared with the corresponding genes in PFI. When the degree of $\mathrm{m}^{6} \mathrm{~A}$ methylation increased in PFIM60 compared with that in $\mathrm{PFI}$, we found the AS of three genes was correlated with $\mathrm{m}^{6} \mathrm{~A}$ modification, namely F-box (Paulownia_LG17G000760) and MSH5 (Paulownia_LG8G001160). To verify the AS of these two genes in PFI and PFIM60, we performed an RT-PCR analysis. We found that for PFIM60, when the degree of $\mathrm{m}^{6} \mathrm{~A}$ methylation increased, the bands of two genes were weakened compared with those for PFI, indicating that the degree of $\mathrm{m}^{6} \mathrm{~A}$ methylation affected AS events (Figure 9; Supplemental Data Figure S2).

\section{Identification of potential candidate genes associated with PaWB}

In the process of invading a host, inherent pathogen-associated molecular patterns called PAMPs or damage-related molecular patterns of the phytoplasma are recognized by pattern recognition receptors in the host defense system, which induces PAMP- 
triggered immunity and activates the downstream defense pathway. To resist PAMP-triggered immunity, phytoplasmas release effectors as signal molecules to regulate signal transduction and disrupt the host defense response. This in turn triggers a series of physiological and biochemical reactions, which results in metabolic disruption in the host plant and development of disease symptoms. Some of the identified DEGs were related to plant-pathogen interactions, plant hormone signal transduction, and plant tillering. Among them, four significantly DEGs were involved in the plant hormone signal transduction pathway: Paulownia14027, which encoded SHORT-ROOT (LSH4); Paulownia26350, which encodes LIGHT-DEPENDENT SHORT HYPOCOTYLS 4 (LSH4); Paulownia_LG17G000277, which encodes histidine-containing phosphotransfer protein 1-like; and Paulownia_LG2G000140, which encodes regulatory protein NPR5-like. One DEG was involved in the plant-pathogen interaction pathway: Paulownia000609, which encodes disease resistance protein RPM1-like. Two DEGs were involved in the carotenoid biosynthesis pathway:

Paulownia_LG11G000307, which encodes phytoene synthase 2; and Paulownia_LG18G000559, which encodes carotenoid cleavage dioxygenase 4 .

The most prominent symptom of PaWB is axillary bud clustering, so we also focused on genes that affect branching and tillering in plants, namely CLAVATA1 (CLV1), CLV2, CLV3 (Nikolaev et al. 2007), WUSCHEL (WUS) (Lenhard et al. 2002), Arabidopsis TOPLESS (TPL)-like transcriptional corepressor (ASP1), SHOOT MERISTEMLESS (STM), ARABIDOPSIS RESPONSE REGULATOR 5 (ARR5), $A R R 6, A R R 7$, and $A R R 15$ (Leibfried et al. 2005). In Arabidopsis, these genes encode proteins that are involved in the WUSCHELCLAVATA negative feedback loop, which is the basic mechanism for maintaining stem cells in shoot apical meristem. We found Paulownia homologs of CLV2 (Paulownia_LG2G000076) and STM (Paulownia_LG15G000976) by mapping the Arabidopsis genes to the Paulownia reference genome using a local BLAST program. These two genes showed significant differences in $\mathrm{m}^{6} \mathrm{~A}$ methylation and expression levels after phytoplasma infection.

We performed a $\mathrm{m}^{6} \mathrm{~A}$ methylated RNA immunoprecipitation quantitative reverse transcription PCR (MeRIP-qRT-PCR) verification on these two candidate genes. The results were consistent with the sequencing results, which verified the accuracy of the sequencing results (Figure 10).

\section{STM and CLV2 maintain the dynamic balance of shoot apical meristem regulated by $\mathrm{m}^{6} \mathrm{~A}$ methylation modification}

Conserved domains were identified in the proteins encoded by the Paulownia homologs of STM and CLV2 (Table 1). Similar to STM, Paulownia_LG15G000976 encodes a homeobox transcription factor with four conserved domains, KNOX2, KNOX1, Homeobox_KN, and ELK. Similar to CLV2, Paulownia_LG2G000076 encodes a protein kinase that contains the domain PLN00113 superfamily. Previous studies have shown that STM and WUS bind to the CLV3 promoter and activate its transcription, and CLV3, CLV1, and CLV2 together maintain the number of undifferentiated stem cells in the shoot apical meristem tissue and regulate the production of normal stem ends. The transcriptome data analysis showed that STM was more highly expressed in PFI than it was in PFIM60, and the $\mathrm{m}^{6} \mathrm{~A}$-seq data analysis showed that $C L V 1, C L V 2$, and $C L V 3$ had higher methylation levels in PFI than in PFIM60.

Table 1

conserved domain analysis for two protein related to PaWB

\begin{tabular}{|c|c|c|c|c|c|c|c|c|}
\hline Gene & Gene ID & Significant & $\mathrm{m} 6 \mathrm{~A}$ & gene & Incomplete & Incomplete & Incomplete & Incomplete \\
\hline \multirow[t]{4}{*}{ STM } & AT1G62360 & - & - & - & KNOX2 & KNOX1 & Homeobox_KN & ELK \\
\hline & Paulownia_LG15G000976 & yes & down & down & KNOX2 & KNOX1 & Homeobox_KN & ELK \\
\hline & Paulownia_LG14G000617 & yes & down & down & KNOX2 & KNOX1 & Homeobox_KN & ELK \\
\hline & Paulownia_LG7G001667 & no & up & down & KNOX2 & KNOX1 & Homeobox_KN & ELK \\
\hline \multirow[t]{2}{*}{ CLV2 } & AT1G65380 & - & - & - & $\begin{array}{l}\text { PLN00113 } \\
\text { superfamily }\end{array}$ & - & - & - \\
\hline & Paulownia_LG2G000076 & yes & down & down & $\begin{array}{l}\text { PLN00113 } \\
\text { superfamily }\end{array}$ & - & - & - \\
\hline
\end{tabular}

\section{Discussion}

\section{$\mathrm{m}^{6} \mathrm{~A}$ modification of genes in PFI and PFIM60}


The $\mathrm{m}^{6} \mathrm{~A}$-seq of the PFI and PFIM60 samples detected 13,837 and 13,505 genes, respectively, that were methylated; overall 12,554 unique genes were $\mathrm{m}^{6} \mathrm{~A}$ methylated. Among the shared $\mathrm{m}^{6} \mathrm{~A}$ methylation-modified genes, 1,886 methylation sites in 1,662 genes were significantly differentially modified between PFI and PFIM60, accounting for $92 \%$ of the total differential methylation sites. Among them, $202 \mathrm{DEGs}$ had significantly different $\mathrm{m}^{6} \mathrm{~A}$ methylation. The overall methylation level was slightly higher in the PFI samples compared with the level in the PFIM60 samples. However, the regions in which methylation was different were similar in the two samples, with nearly $40 \%$ of the modified regions located in the 3 ' UTRs.

\section{$\mathrm{m}^{6} \mathrm{~A}$ methylation modification regulates the expression of genes related to PaWB}

Phytoplasma infection of $P$. fortunei releases effectors that disturb the plant's immune response. The effectors can interact directly with key plant immune-related genes or can disrupt the immune response by disrupting immune signal transduction. The association analysis of the $\mathrm{m}^{6} \mathrm{~A}$-seq data and transcriptome sequences identified genes related to plant-pathogen interaction, plant hormone signal transduction, and plant tillering. LSH4 (Paulownia26350) was predicted to be involved in the plant-pathogen interaction and signal transduction pathways. Constitutive expression of $\mathrm{LSH} 4$ in the shoot apex inhibited leaf growth in the vegetative phase as well as the formation of extra shoots or shoot organs in flowers in the reproductive phase. The methylation modification and transcription levels of $L S H 4$ were significantly up-regulated in PFI compared with the levels in PFIM60. We speculated that phytoplasma infection of Paulownia increased the $\mathrm{m}^{6} \mathrm{~A}$ modification level in the $3^{\prime}$ UTR region of $L S H 4$, which enhanced the stability of $L S H 4$ mRNA and increased its expression level, thereby promoting the occurrence of PaWB.

The symptom of axillary bud clustering caused by PaWB is closely related to the development of shoot apical meristem. In Arabidopsis, three master regulators, STM, WUS, and CLV3, are critical for stem cell specification in shoot apical meristem. STM interacts with WUS in vivo and recruits CLV3 to express shoot apical meristem. In Paulownia, WUS expression was relatively low and was similar in PFI and PFIM60, whereas STM expression was higher in PFI than it was in PFIM60. We speculated that the increased methylation level in the $3^{\prime}$ UTR region of STM in PFI maintained its stable expression. In Arabidopsis, the $\mathrm{m}^{6} \mathrm{~A}$ methylase FIP37 affected the expression of WUS and STM and regulated the development of shoot apical meristem. These results suggested that a $\mathrm{m}^{6} \mathrm{~A}$ methylase may also be involved in regulating STM expression in Paulownia. However, this possibility needs to be confirmed in further studies.

\section{The relationship between $\mathrm{m}^{6} \mathrm{~A}$ modification and alternative splicing of PaWB-related genes}

Alternative splicing is a key regulatory mechanism that participates in many physiological processes, controls plant development, and increases the complexity of the proteome and transcriptome. In addition, alternative splicing plays a vital role in plant defense response and photosynthesis (Wang \& Brendel 2006). Compared with PFI, PFIM60 found a total of 282 SE-type alternative splicing genes and $84 \mathrm{MXE}$-type alternative splicing genes. To determine the relationship between alternative splicing and PaWB, we studied the genes associated with alternative splicing events in PaWB-infected Paulownia. The combined analysis of m6A modification and alternative splicing found that when the degree of m6A methylation increased, there was a correlation between alternative splicing and m6A modification of the two genes, namely F-box (Paulownia_LG17G000760) and MSH5 (Paulownia_LG8G001160). The gene encoding F-box is involved in alternative splicing events. The F-box protein is a subunit of the SCF complex and plays an important role in plant hormone signal transduction and regulation of plant development and growth (Gonzalez et al. 2017). JA can regulate the growth of most plants, including their ability to adapt to adversity and to resist the invasion of pathogens. The F-box protein COI1 is the receptor of JA, and the response with JA dependence as the core is mediated by the Skp1/Cullin/F-box E3 ubiquitin ligase complex containing COI1 (Gonzalez et al. 2017). The SCF complex can degrade JA, causing MYC2 to be released, thereby expressing genes that respond to JA (Liu et al. 2017). In short, F-box protein may be involved in regulating the growth of Paulownia to improve its ability to adapt to stress. Due to the lack of reliable data, this speculation still needs further research to verify. MSH5 is a homologue of DNA mismatch recognition protein (Muts). DNA mismatch repair (MMR) is a highly conserved biological pathway that can improve the fidelity of DNA replication and recombination. When the MutS protein recognizes small loops of mismatched and unpaired nucleotides, it initiates MMR(Jiricny 2013; Spampinato 2017). Previous studies have shown that Arabidopsis and other plants encode MutS protein homologues (MSH) that are conserved in other eukaryotes. Plants lacking MSH7 show significantly faster germination rates and longer germination rates during the juvenile vegetative period. In primary roots, the number of stem leaves and axillary and lateral inflorescences is higher than that of the wild type (Chirinos-Arias \& Spampinato 2020; Gonzalez \& Spampinato 2020). These findings indicate that the growth of mutant plants seems to be caused by damage to cell cycle 
checkpoints, which allow cells to divide without proper DNA repair, and its role in the process of phytoplasma infection of Paulownia needs further development explore.

\section{Conclusions}

We applied $\mathrm{m}^{6} \mathrm{~A}$-seq to determine methylation levels in phytoplasma-infected Paulownia. We found that the $\mathrm{m}^{6} \mathrm{~A}$ modifications differed from those previously reported in model plants. We speculated that the Paulownia genome had a novel $\mathrm{m}^{6} \mathrm{~A}$ modification motif. DEGs associated with PaWB were detected by transcriptomic analysis. Also analyzed the effect of m6A methylation on alternative splicing. In future studies, we plan to verify genes directly related to PaWB and methylation-related enzymes in Paulownia to elucidate the pathogenicity mechanism of PaWB caused by phytoplasma invasion.

\section{Methods}

\section{Plant materials}

The experimental plant materials used in this study were obtained from the Forest Biotechnology Laboratory of the Institute of Paulownia, Henan Agricultural University, Zhengzhou, China, and the permission to collect the $P$. fortunei has been obtained. The plant materials were grown on $1 / 2 \mathrm{MS}$ medium in 100-ml Erlenmeyer flasks for 30 days. Then, $1.5-\mathrm{cm}$ terminal buds from the PFI plants were transferred into 1/2 MS medium contain $60 \mathrm{mg} \cdot \mathrm{L}^{-1} \mathrm{MMS}$ (PFIM60 samples) (Figure 11a) or $0 \mathrm{mg} \cdot \mathrm{L}^{-1} \mathrm{MMS}$ (PFI samples) (Figure 11b). Two seedlings were cultured in each bottle and 90 bottles were cultivated for each sample. After 30 days, the obtained samples were frozen in liquid nitrogen and stored at $-80^{\circ} \mathrm{C}$ until used.

\section{Antibody enrichment and sequencing library construction}

Total RNA extraction and quality and quantity assessing were performed as described previously. More than $200 \mu \mathrm{g}$ total RNA was used to isolate poly $(A)$ mRNA with poly( $T$ ) oligo-attached magnetic beads (Invitrogen). After purification, the mRNA fractions were fragmented into approximately 100 -nt long oligonucleotides using divalent cations under elevated temperature. The cleaved RNA fragments were incubated for $2 \mathrm{~h}$ at $4^{\circ} \mathrm{C}$ with $\mathrm{m}^{6} \mathrm{~A}$-specific antibody (No. 202003, Synaptic Systems, Germany) in IP buffer (50 mM Tris- $\mathrm{HCl}, 750 \mathrm{mM} \mathrm{NaCl}, 0.5 \%$ Igepal CA-630) supplemented with bovine serum albumin $\left(0.5 \mu \mathrm{g} \cdot \mu \mathrm{L}^{-1}\right)$. The mixture was incubated with protein-A beads and eluted with elution buffer $\left(1 \times I P\right.$ buffer and $\left.6.7 \mathrm{mM} \mathrm{m}{ }^{6} \mathrm{~A}\right)$. The eluted RNA was precipitated with $75 \%$ ethanol. The eluted $\mathrm{m}^{6} \mathrm{~A}$-containing fragments (IP) and untreated input control fragments were converted to form the final cDNA library according to the strand-specific library preparation dUTP method. We constructed four $\mathrm{m}^{6} \mathrm{~A}$-seq libraries (PFI_1_IP, PFI_2_IP, PFIM60_1_IP, PFI-M60_2_IP) and four RNA-seq libraries (PFI_1_IP, PFI_2_IP, PFI-M60_1_IP, PFI-M60_2_IP). The average insert size for the paired-end libraries was approximately $100 \pm 50$ bp. Paired-end $2 \times 150$ bp sequencing was performed on an Illumina Novaseq ${ }^{\text {TM }} 6000$ (Biotech Itd, Hangzhou, China) platform following the manufacturer's recommended protocol.

\section{Alignment of reads to the reference genome and visualization of $\mathrm{m}^{6} \mathrm{~A}$ peaks}

Cutadapt (Martin et al. 2011) and perl in-house scripts were used to remove reads that contained adaptor contamination, low quality bases, and/or undetermined bases. Sequence quality was verified using FastQC

(http://www.bioinformatics.babraham.ac.uk/projects/fastqc/). Bowtie (Langmead et al. 2012) (with default parameters) was used to map reads to the $P$. fortunei reference genome. Mapped reads of the IP and input libraries were input into the exomePeak package in $\mathrm{R}$ (Meng et al. 2014) to identify $\mathrm{m}^{6} \mathrm{~A}$ peaks (in BED or BAM format) for visualization using the UCSC Genome Browser or Integrative Genomics Viewer (IGV) software (http://www.igv.org/).

\section{Transcription level analysis}


StringTie (Pertea et al. 2015) software was used to determine the mRNA expression levels in the input libraries by calculating FPKM (FPKM=[total exon fragments/mapped reads (millions) xexon length $(\mathrm{kb})]$ ). The differentially expressed mRNAs were selected using the edgeR package in $\mathrm{R}$ with a threshold of log2 (fold change) $>1$ or $<-1$ and $p$ value $<0.05$ (Robinson et al. 2010).

\section{Discernment of $\mathrm{m}^{6} \mathrm{~A}$ topological patterns}

MEME (Bailey et al. 2009) and HOMER (Heinz et al. 2010) were used to find de novo and known motifs in the differential modified genes. Localization of the motifs with respect to peak summit was performed using in-house perl scripts. Called peaks were annotated by intersection with gene architecture using ChIPseeker (Yu et al. 2015).

\section{$\mathrm{m}^{6} \mathrm{~A}$ MeRIP-qRT-PCR}

The $\mathrm{m}^{6} \mathrm{~A}$ methylated RNA immunoprecipitation (MeRIP) assay was adapted from a previously reported protocol (Dominissini et al. 2013). Briefly, approximately $300 \mathrm{mg}$ total RNA was extracted and isolated using an mRNA screening kit. Each biological replicate for $\mathrm{m}^{6} \mathrm{~A}$-seq started with $400 \mathrm{mg}$ of total RNA, which yielded approximately $10 \mathrm{mg}$ of double poly $(\mathrm{A})$ selected mRNA. Then, the mRNA was treated with mRNA fragmentation reagent and fragmentation of the $300 \mathrm{~mL}$ poly(A) RNA solution was performed at $94^{\circ} \mathrm{C}$ for exactly 5 min using a thermocycler. The fragmentation reaction was stopped by adding $50 \mathrm{~mL}$ of stop buffer to a final volume of 350 $\mathrm{mL}$ and immediately put on ice. Approximately $100 \mathrm{ng}$ mRNA was taken out as the input sample and $150 \mathrm{~mL}$ of pre-equilibrated $\mathrm{m}^{6} \mathrm{~A}$ Dynabeads was added to the remaining fragmented RNA to a final volume of $500 \mathrm{~mL}$. The fragmented RNA was allowed to bind to the $\mathrm{m}^{6} \mathrm{~A}$-Dynabeads at $4^{\circ} \mathrm{C}$ while rotating (tail-over-head) at seven rotations per minute for $2 \mathrm{~h}$. Then, the tubes containing the samples were placed on a magnet and the bead complexes were allowed to cluster until the solution became clear. The 500-mL liquid phase or supernatant was discarded because it contained $\mathrm{m}^{6} \mathrm{~A}$ negative fragments that were not captured by the anti-m ${ }^{6} \mathrm{~A}$ antibody. The $\mathrm{m}^{6} \mathrm{~A}$-Dynabeads-RNA complexes were resuspended in $500 \mathrm{~mL} \mathrm{~m}{ }^{6} \mathrm{~A}$ binding buffer, incubated for $3 \mathrm{~min}$ at room temperature, and the clear supernatant was removed after placing the beads on a magnet. This step was repeated with $500 \mathrm{~mL}$ low salt buffer, then with $500 \mathrm{~mL}$ high salt buffer. (The 3-min incubation time should not be exceeded to prevent release of the RNA from the beads.) This step was then repeated twice with $500 \mathrm{~mL}$ TET buffer. The obtained immunoprecipitated product was prepared by resuspending in $100 \mathrm{~mL}$ of proteinase $\mathrm{K}$ buffer and the obtained input sample was thawed. Then, $107 \mathrm{~mL}$ of RIP wash buffer, $15 \mathrm{ml}$ of $10 \%$ SDS, and $18 \mathrm{~mL}$ of proteinase $\mathrm{K}$ were added to a total volume of $150 \mathrm{~mL}$, and the mixture was incubated at $55^{\circ} \mathrm{C}$ for 30 min with shaking to digest the antibody from the magnetic beads. After incubation, the supernatant was removed and $250 \mathrm{~mL}$ of RIP wash buffer was added to the supernatant. Next, $400 \mathrm{~mL}$ of phenol/chloroform was added to each tube, which was then vortexed for $15 \mathrm{~s}$, and 0.1 times the volume was added. RNA precipitation was promoted by adding $3 \mathrm{M} \mathrm{NaAc}$ and $2 \mathrm{~mL}$ GlycoBlue at $-20^{\circ} \mathrm{C}$ for $1 \mathrm{~h}$. The tubes were centrifuged at $14,000 \mathrm{rpm}$ for $20 \mathrm{~min}$ at $4^{\circ} \mathrm{C}, 75 \%$ ethanol precipitation was performed twice, and the pellet was blown dry, then dissolved in $10 \mathrm{~mL}$ RNA-free water and tested.

\section{Declarations}

\section{Ethics approval and consent to participate}

This article does not contain any studies with human participants or animals performed by the authors. Experimental research and field studies on plants, including the collection of plant material, were carried out in accordance with relevant guidelines and regulations. We confirm that all experimental protocols were approved by the Forest Biotechnology Laboratory of the Institute of Paulownia, Henan Agricultural University, Zhengzhou, China.

\section{Consent for publication}

Not applicable

\section{Competing interests}

The authors declare that they have no competing interests. 
The datasets generated and/or analysed during the current study are available in the [NCBI] repository, [SRA accession:

PRJNA783736 and PRJNA624264]. The $P$. fortunei used in this study came from the Forest Biotechnology Laboratory of the Institute of Paulownia, Henan Agricultural University, Zhengzhou, China., and the permission to collect the $P$. fortunei has been obtained.

\section{Competing interests}

The authors declare that they have no competing interests.

\section{Funding}

This work was supported by the Academic Scientist fund for Zhongyuan scholars of Henan Province (Grant No. 2018[99]) and Leading Talents of Zhongyuan Science and Technology Innovation.

\section{Authors' contributions}

GF conceived and designed the experiments. $\mathrm{HY}$ and $\mathrm{YC}$ provided suggestions on the experimental design and analyses. $\mathrm{PX}$ and $\mathrm{SH}$ analyzed the data and wrote the paper. $\mathrm{ZX}, \mathrm{XL}, \mathrm{HY}, \mathrm{YC}$ and GF revised the manuscript. All authors read and approved the manuscript.

\section{Acknowledgment}

We thank Margaret Biswas, PhD, from Liwen Bianji (Edanz) (www.liwenbianji.cn/) for editing the English text of a draft of this manuscript.

\section{Authors' information}

Pingluo Xu and Shunmou Huang contributed equally to this work.

\section{References}

1. Bailey TL, Boden M, Buske FA, Frith M, CE Grant, Clementi L et al. MEME SUITE: tools for motif discovery and searching. Nucleic Acids Research. 2009; 37(Web Server):W202-W208.

2. Barbazuk WB, Fu Y, McGinnis KM. Genome-wide analyses of alternative splicing in plants: opportunities and challenges. Genome Research. 2008; 18: 1381-1392.

3. Chirinos-Arias M C, Spampinato C P. Growth and development of AtMSH7 mutants in Arabidopsis thaliana. Plant Physiology and Biochemistry. 2020; 146: 329-336.

4. Deng X, Chen K, Luo GZ, Weng X, Ji Q, Zhou T, He C. Widespread occurrence of N6-methyladenosine in bacterial mRNA. Nucleic Acids Res. 2015; 27 43(13):6557-67.

5. Dominissini D, Moshitch-Moshkovitz S, Schwartz S, Salmon-Divon M, Ungar L, Osenberg S et al. Topology of the human and mouse m6A RNA methylomes revealed by m6A-seq. NATURE. 2012; 485(7397):201-206.

6. Dominissini D, Moshitch-Moshkovitz S, Salmon-Divon M, Amariglio N, Rechavi G. Transcriptome-wide mapping of N6methyladenosine by m6A-seq based on immunocapturing and massively parallel sequencing. Nature Protocols. 2013; 8(1):176189.

7. Duan HC, Wei LH, Zhang C, Wang Y, Chen L, Lu Z et al. ALKBH10B is An RNA N6-Methyladenosine Demethylase Affecting Arabidopsis Floral Transition. Plant Cell. 2017; 29:2995-3011.

8. Geng XS, Shu JP, Wang HJ, Zhang W. Research Advance on Transmission, Epidemic and Control of Phytoplasmal Disease. Chinese Agricultural Science Bulletin. 2015; 031(025):164-170.

9. Heinz S, Benner C, Spann N, Bertolino E, Lin YC, Laslo P et al. Simple Combinations of Lineage-Determining Factors Prime cisRegulatory Elements Required for Macrophage and B-Cell Identities. Molecular cell. 2010; 38(4):576-589.

10. Gallinger J, Gross J. Unraveling the Host Plant Alternation of Cacopsylla pruni - Adults but Not Nymphs Can Survive on Conifers Due to Phloem/Xylem Composition. Frontiers in Plant Science. 2018; 9:484.

11. Gonzalez LE, Keller K, Chan KX, Gessel MM, and Thines BC. Transcriptome analysis uncovers Arabidopsis F-BOX STRESS INDUCED 1 as a regulator of jasmonic acid and abscisic acid stress gene expression. Bmc Genomics. 2017; 18:533. 
12. Gonzalez V, Spampinato C P. The mismatch repair protein MSH6 regulates somatic recombination in Arabidopsis thaliana. DNA Repair. 2020; 87: 102789.

13. Jiricny J. Postreplicative mismatch repairCold Spring Harb. Perspect. Biol. 2013; 5:a012633.

14. Jia G, Fu Y, Zhao X, Dai Q, Zheng G, Yang Y et al. N6-Methyladenosine in nuclear RNA is a major substrate of the obesityassociated FTO. Nature Chemical Biology. 2011; 7(12):885-887.

15. Kosovac A, Johannesen J, Krstić O, Mitrović M, Cvrković T, Toševski I et al. Widespread plant specialization in the polyphagous planthopper Hyalesthes obsoletus (Cixiidae), a major vector of stolbur phytoplasma: Evidence of cryptic speciation. PLoS ONE. 2018; 13(5): e0196969.

16. Langmead B, Salzberg SL. Fast gapped-read alignment with Bowtie 2. NATURE METHODS. 2012; 9(4):357-359.

17. Lenhard M, Jürgens G, Laux T. The WUSCHEL and SHOOTMERISTEMLESS genes fulfil complementary roles in Arabidopsis shoot meristem regulation. Development. 2002; 129(13):3195-3206.

18. Leibfried A, To JPC, Busch W, Stehling S, Kehle A, Demar M et al. WUSCHEL controls meristem function by direct regulation of cytokinin-inducible response regulators. Nature. 2005; 438(7071):1172-1175.

19. Li Z, Weng H, Su R, Weng X, Zuo Z, Li C et al. FTO Plays an Oncogenic Role in Acute Myeloid Leukemia as a N6-Methyladenosine RNA Demethylase. Cancer Cell. 2017; 31(1):127-141.

20. Lin S, Choe J, Du P, Triboulet R, Gregory RI. The m(6)A Methyltransferase METTL3 Promotes Translation in Human Cancer Cells. Molecular cell. 2016; 62(3):335-345.

21. Liu N, Parisien M, Dai Q, Zheng G, He C, Pan T. Probing N6-methyladenosine RNA modification status at single nucleotide resolution in mRNA and long noncoding RNA. RNA. 2013; 19:1848-1856.

22. Liu J, Yue Y, Han D, Wang X, Fu Y, Zhang L et al. A METTL3-METTL14 complex mediates mammalian nuclear RNA N6-adenosine methylation. Nature Chemical Biology. 2014; 10:93-95.

23. Liu N, Dai Q, Zheng G, He C, Parisien M, Pan T. N6-methyladenosine-dependent RNA structural switches regulate RNA-protein interactions. Nature. 2015; 518: 60-564.

24. Liu H, Carvalhais LC, Schenk PM, and Dennis PG. Effects of jasmonic acid signalling on the wheat microbiome differ between body sites. Scientific Reports. 2017; 7:41766.

25. Li ZR, Shi J, Yu L, Zhao XZ, Ran LL, Hu DY et al. N6 -methyl-adenosine level in Nicotiana tabacum is associated with tobacco mosaic virus. Virology Journal. 2018; 15(1):87.

26. Luo GZ, MacQueen A, Zheng G, Duan H, Dore LC, Lu Z et al. Unique features of the m6A methylome in Arabidopsis thaliana. Nat Commun. 2014; 28(5):5630.

27. Martin M. Cutadapt removes adapter sequences from high-throughput sequencing reads. Embnet Journal. 2011; 17(1)10-12.

28. Meng J, Lu Z, Liu H, Zhang L, Zhang S, Chen Y et al. A protocol for RNA methylation differential analysis with MeRIP-Seq data and exomePeak R/Bioconductor package. Methods. 2014; 69(3):274-281.

29. Meyer KD, Saletore Y, Zumbo P, Elemento O, Mason CE, Jaffrey SR. Comprehensive analysis of mRNA methylation reveals enrichment in 3' UTRs and near stop codons. Cell. 2012; 22; 149(7):1635-46.

30. Nikolaev SV, Penenko AV, Lavreha VV, Mjolsness ED, Kolchanov N. A model study of the role of proteins CLV1, CLV2, CLV3, and WUS in regulation of the structure of the shoot apical meristem. Russian Journal of Developmental Biology. 2007; 38(6):383388.

31. Pertea M, Pertea GM, Antonescu CM, Chang TC, Mendell JT, Salzberg SL. StringTie enables improved reconstruction of a transcriptome from RNA-seq reads. Nature Biotechnology. 2015; 33(3):290-295.

32. Ping XL, Sun BF, Wang L, Xiao W, Yang X, Wang WJ, et al. Mammalian WTAP is a regulatory subunit of the RNA N6methyladenosine methyltransferase. Cell Res. 2014; 24: 177-189.

33. Robinson MD, Mccarthy DJ, Smyth GK. edgeR: a Bioconductor package for differential expression analysis of digital gene expression data. Bioinformatics. 2010; 26:139.

34. Schwartz S, Agarwala SD, Mumbach MR, Jovanovic M, Mertins P, Shishkin A et al. High-resolution mapping reveals a conserved, widespread, dynamic mRNA methylation program in yeast meiosis. Cell. 2013; 5; 155(6):1409-21.

35. Shen L, Liang Z, Gu X, Chen Y, Teo ZWN, Hou X et al. N6-Methyladenosine RNA Modification Regulates Shoot Stem Cell Fate in Arabidopsis. Developmental Cell. 2016; 38:186-200.

Page 10/19 
36. Spampinato CP. Protecting DNA from errors and damage: an overview of DNA repair mechanisms in plants compared to mammals. Cell. Mol. Life Sci. 2017; 74:1693-1709

37. Wang BB, and Brendel V. Genomewide Comparative Analysis of Alternative Splicing in Plants. Proc Natl Acad Sci USA. 2006; 103:7175.

38. Wang X, Lu Z, Gomez A, Hon GC, Yue Y, Han D. N6-methyladenosine-dependent regulation of messenger RNA stability. Nature. 2013; 505: 117-120.

39. Wang X, Zhao BS, Roundtree IA, Lu Z, Han D, Ma H et al. N6-methyladenosine Modulates Messenger RNA Translation Efficiency. Cell. 2015; 161(6): 1388-1399.

40. Wang Z, Li B, Li Y, Zhai X, Dong Y, Deng M et al. Identification and characterization of long noncoding RNA in Paulownia tomentosa treated with methyl methane sulfonate. Physiology and Molecular Biology of Plants. 2018; 24:325-334.

41. Wei LH, Song P, Wang Y, Lu Z, Tang Q, Yu Q et al. The m6A Reader ECT2 Controls Trichome Morphology by Affecting mRNA Stability in Arabidopsis. Plant Cell. 2018; 30:968-985.

42. Yang Y, Hsu PJ, Chen YS, Yang YG. Dynamic transcriptomic m6A decoration: writers, erasers, readers and functions in RNA metabolism. Cell Research. 2018; 8:616-624.

43. Yu G, Wang LG, He QY. ChIPseeker: an R/Bioconductor package for ChIP peak annotation, comparison and visualization. Bioinformatics. 2015; 31(14):2382-2383.

44. Zhang C, Samanta D, Lu H, Bullen JW, Zhang H, Chen I et al. Hypoxia induces the breast cancer stem cell phenotype by HIFdependent and ALKBH5-mediated m6A-demethylation of NANOG mRNA. Proceedings of the National Academy of Sciences. 2016; 113(14):E2047-56.

45. Zhao BS, Wang X, Beadell AV, Lu Z, Shi H, Kuuspalu A et al. m6A-dependent maternal mRNA clearance facilitates zebrafish maternal-to-zygotic transition. Nature. 2017; 542(7642):475-478.

46. Zhao X, Yang Y, Sun BF, Shi Y, Yang X, Xiao W et al. FTO-dependent demethylation of N6-methyladenosine regulates mRNA splicing and is required for adipogenesis. Cell Research. 2014; 24(12):1403-1419.

47. Zheng G, Dahl JA, Niu Y, Fedorcsak P, Huang CM, Li CJ et al. ALKBH5 Is a Mammalian RNA Demethylase that Impacts RNA Metabolism and Mouse Fertility. Molecular Cell. 2013; 49(1):18-29.

48. Zhong S, Li H, Bodi Z, Button J, Vespa L, Herzog M et al. MTA Is an Arabidopsis Messenger RNA Adenosine Methylase and Interacts with a Homolog of a Sex-Specific Splicing Factor. THE PLANT CELL ONLINE. 2008; 20(5):1278-1288.

\section{Figures}


Spearman Correlation of Read Counts

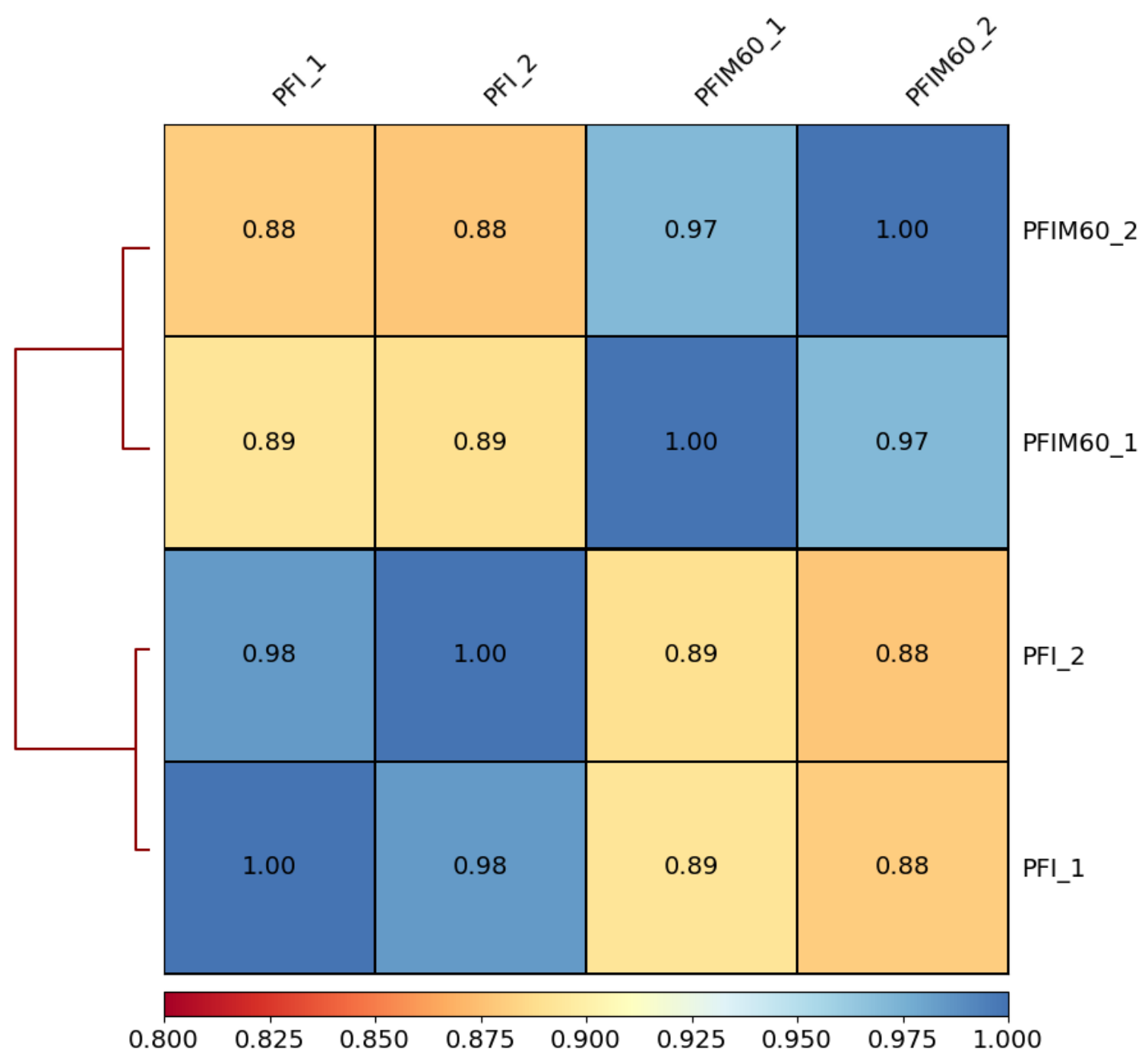

Figure 1

Heatmap correlation coefficient analysis between biological replicates 


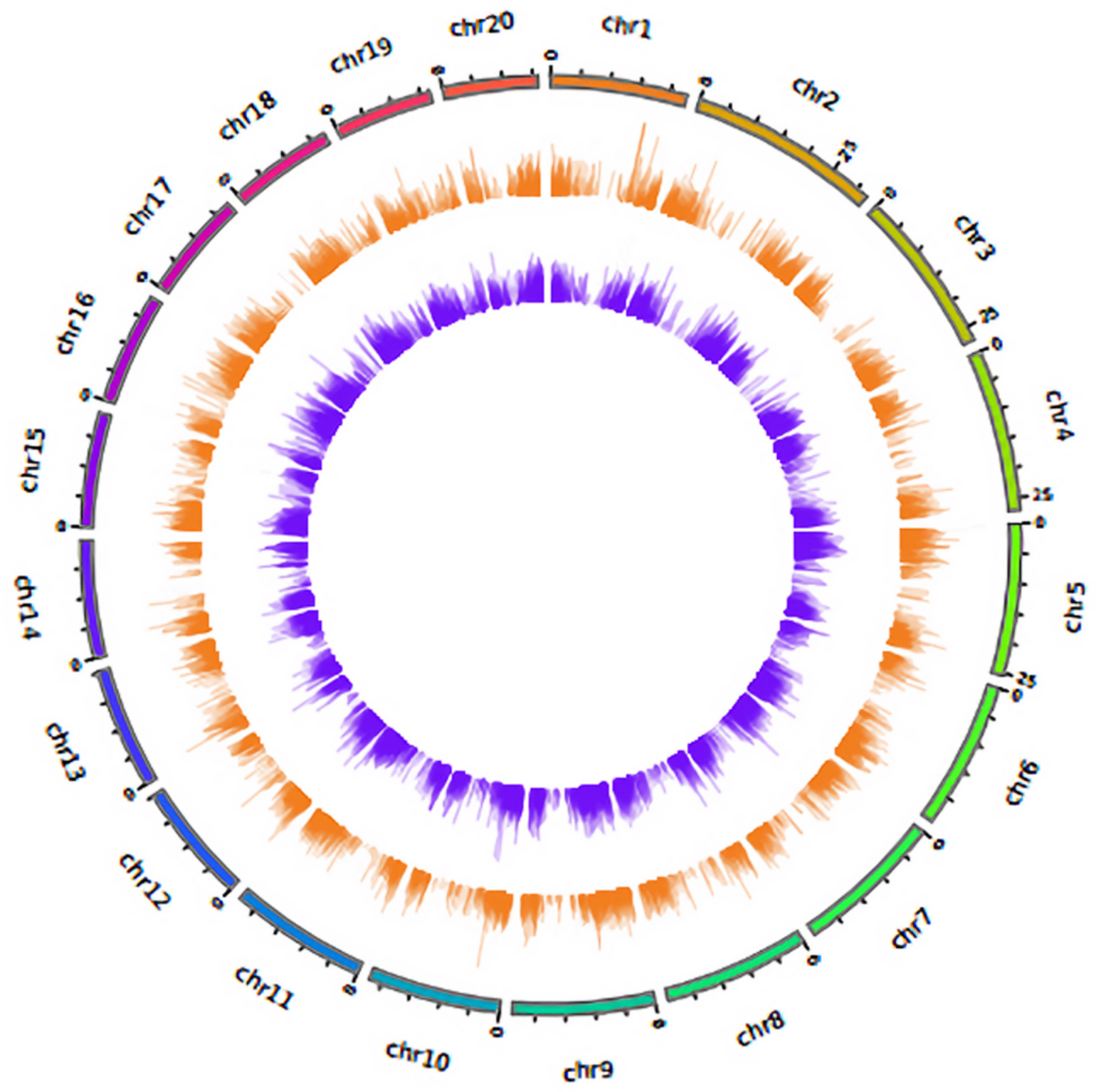

Figure 2

$\mathrm{m}^{6} \mathrm{~A}$ modification map of $P$. fortune. the outermost circle is the chromosome distribution, the second circle is the distribution of PFI m6A peak positions on the chromosomes, and the third circle is the distribution of PFIM60 m6A peak positions on the chromosomes. 
a

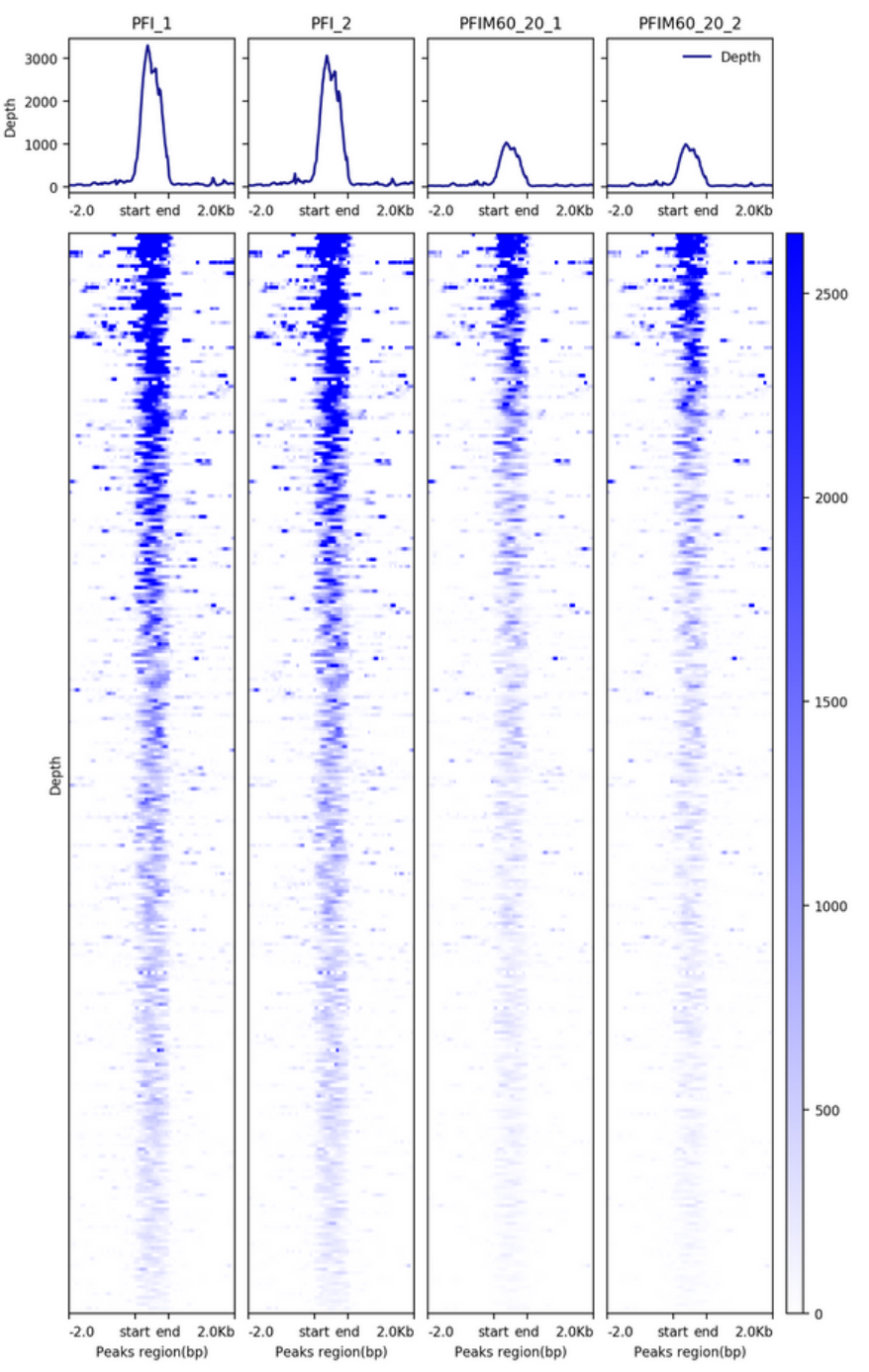

b

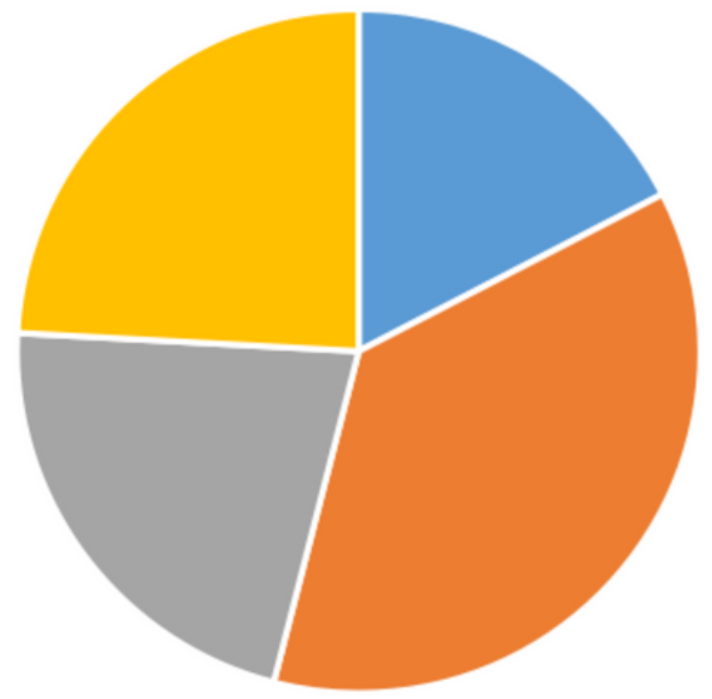

- 5' UTR (17.41\%)

- 3' UTR (36.59\%)

" 1st Exon (21.85\%)

- Other Exon (24.15\%)

\section{Figure 3}

Peak enrichment area. (a), Enrichment of peak at the transcription start site in 4 samples, and the Peak distribution of the bondable region near the TSS is shown in the form of a heat map. (b), Peak enrichment on genetic elements.

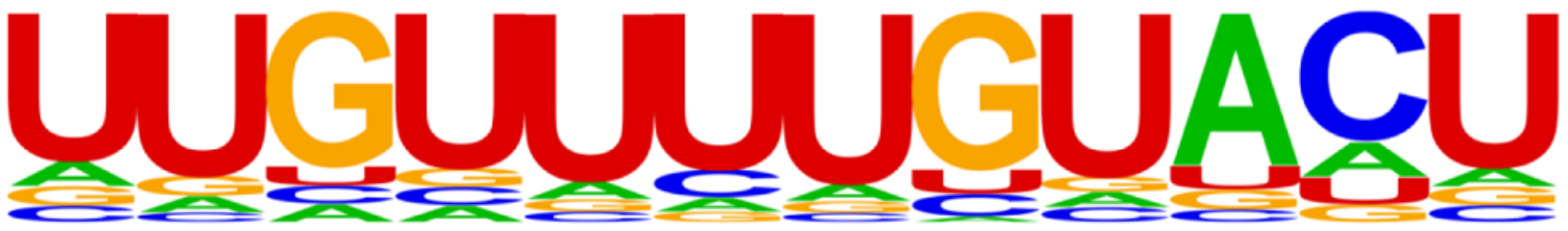

Figure 4

A higher proportion of motifs: UUGUUUUGUACU. 


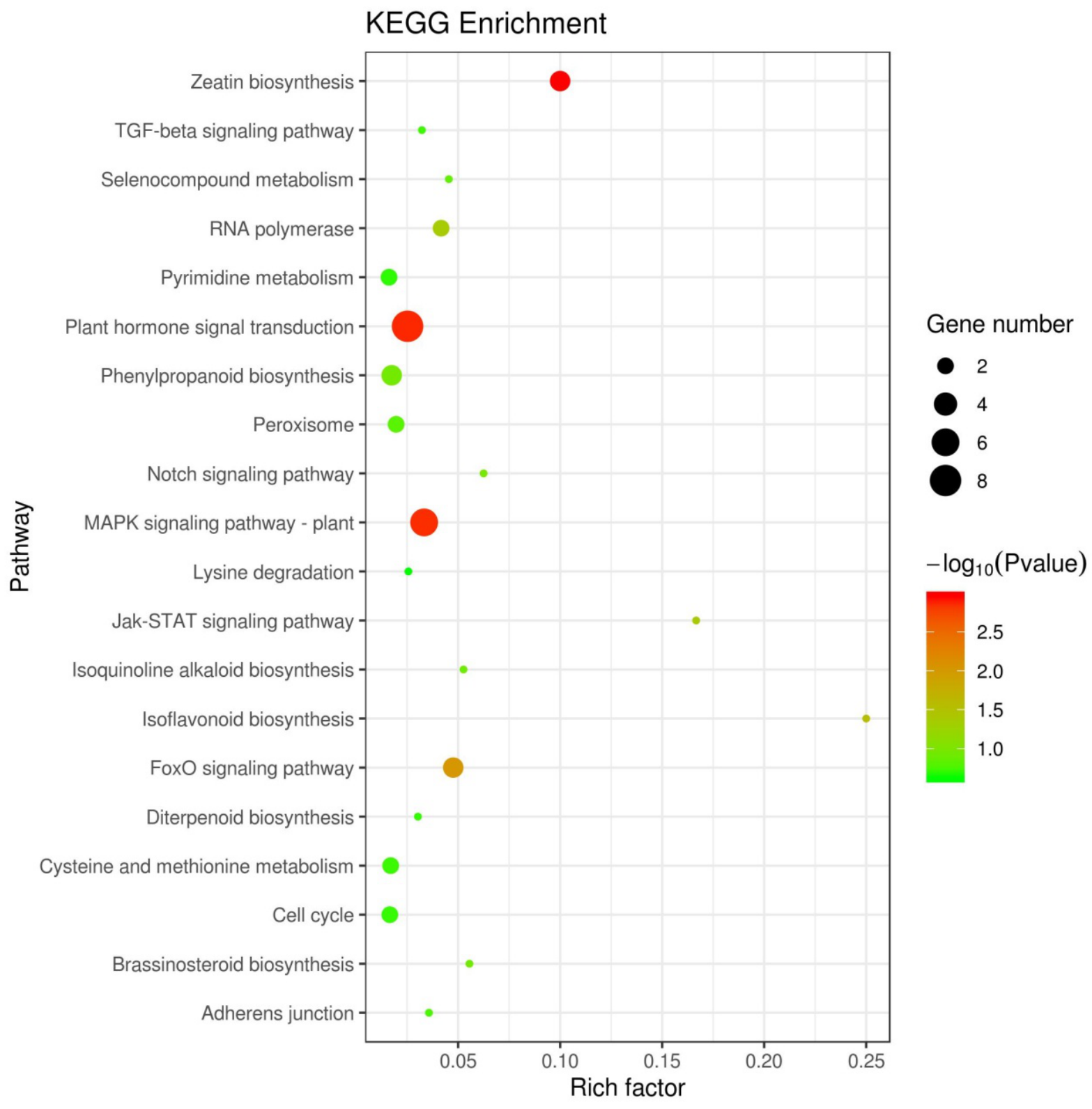

Figure 5

KEGG Enrichment analysis of $\mathrm{m}^{6} \mathrm{~A}$ methylation attenuated gene after $60 \mathrm{mg} \cdot \mathrm{L}-1 \mathrm{MMS}$ treatment. 


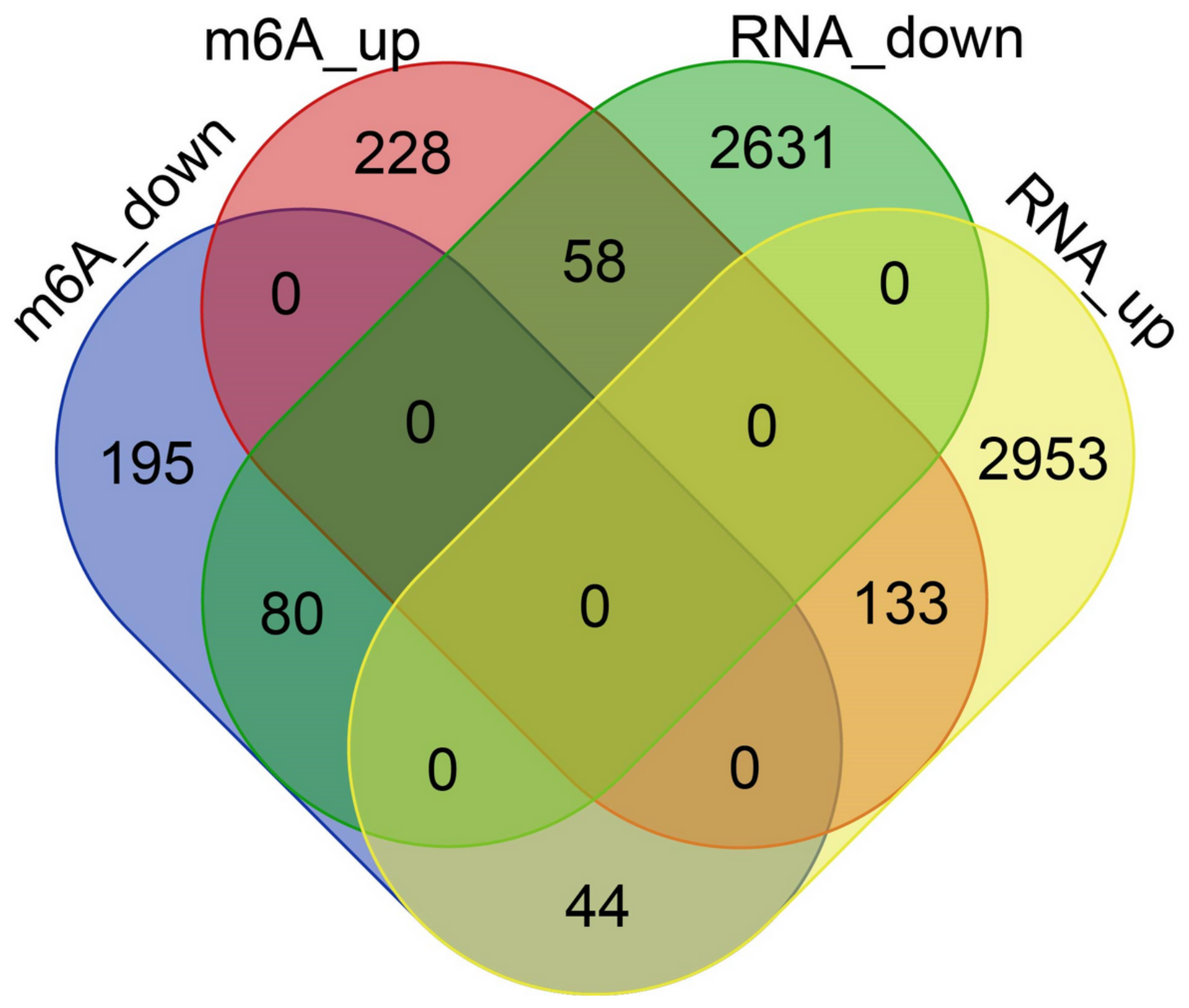

Figure 6

Functional annotation and pathways enrichment of differentially expressed genes. (a), GO function annotation of differentially expressed genes. (b), statistics of KEGG Pathway enrichment. 
a

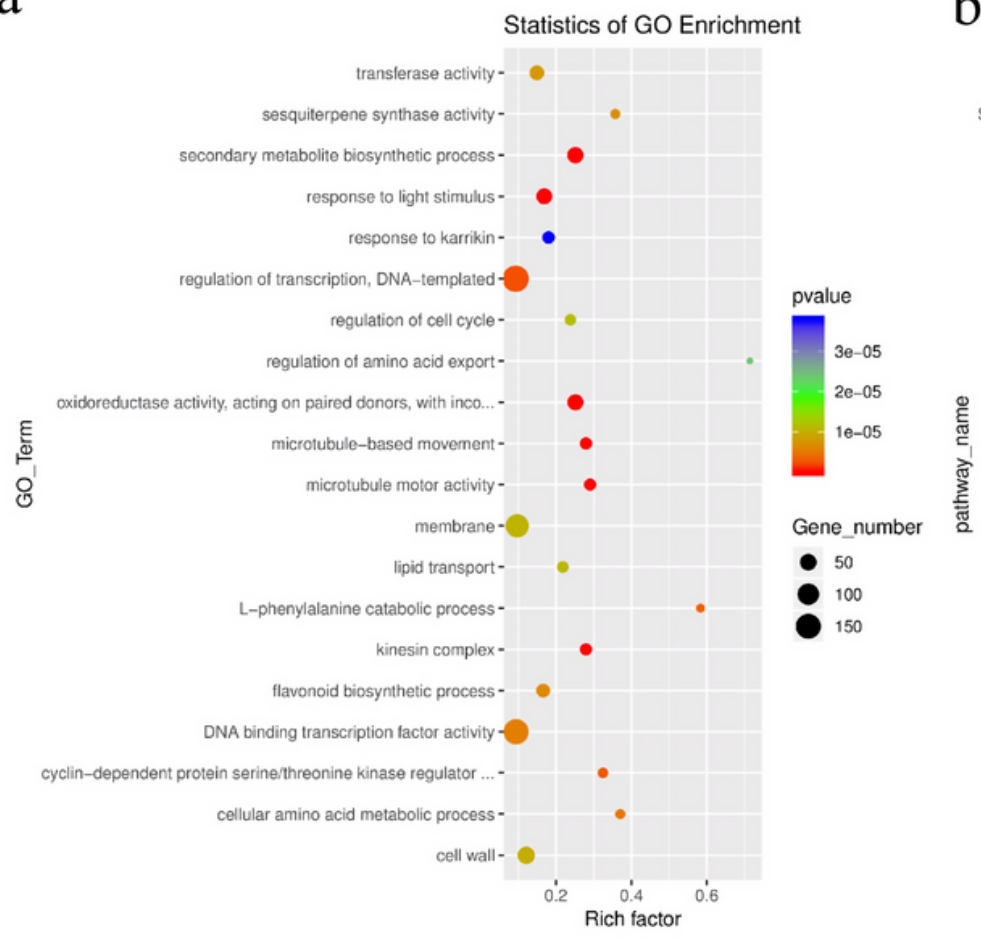

b

Statistics of Pathway Enrichment

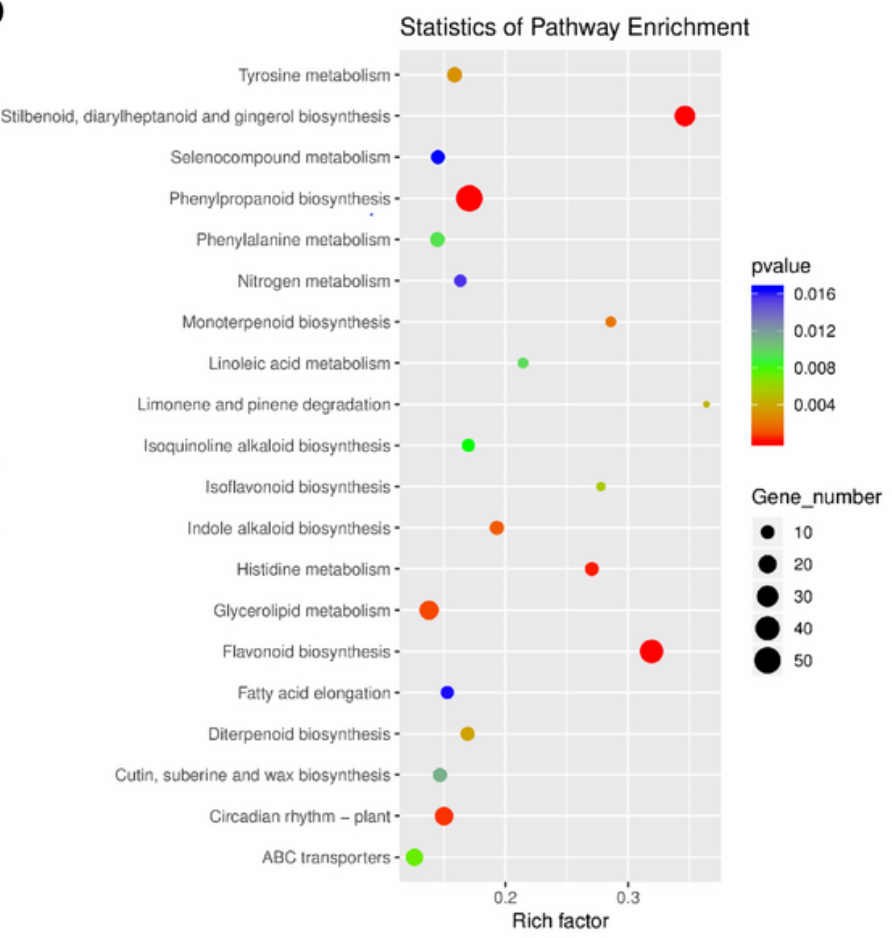

Figure 7

Four relationships were detected between the m6A methylation levels and gene expression.

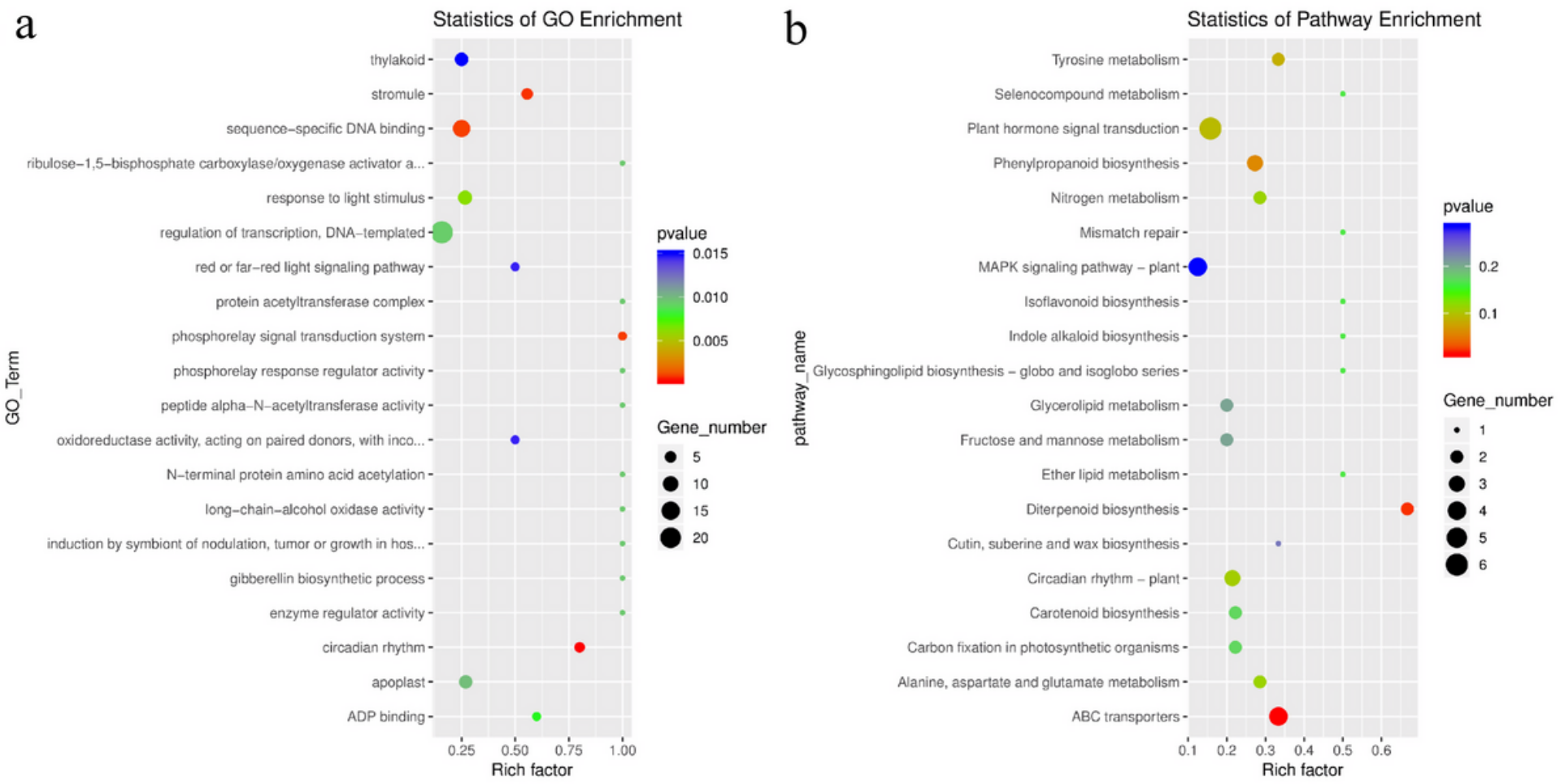

\section{Figure 8}

Functional annotation and pathways of differential peak and differentially expressed genes 

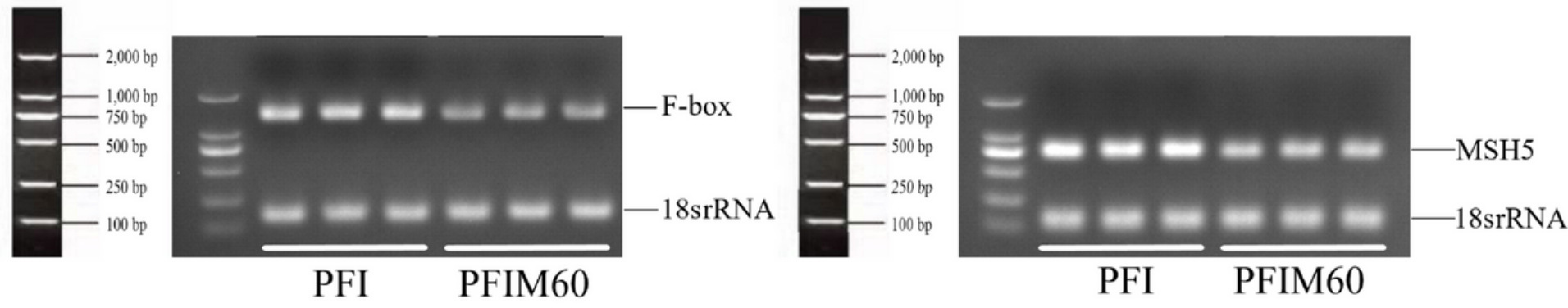

Figure 9

RT-PCR verification of F-box and MSH5 in PFI and PFIM60, respectively. 18s rRNA is an internal reference gene.

STM

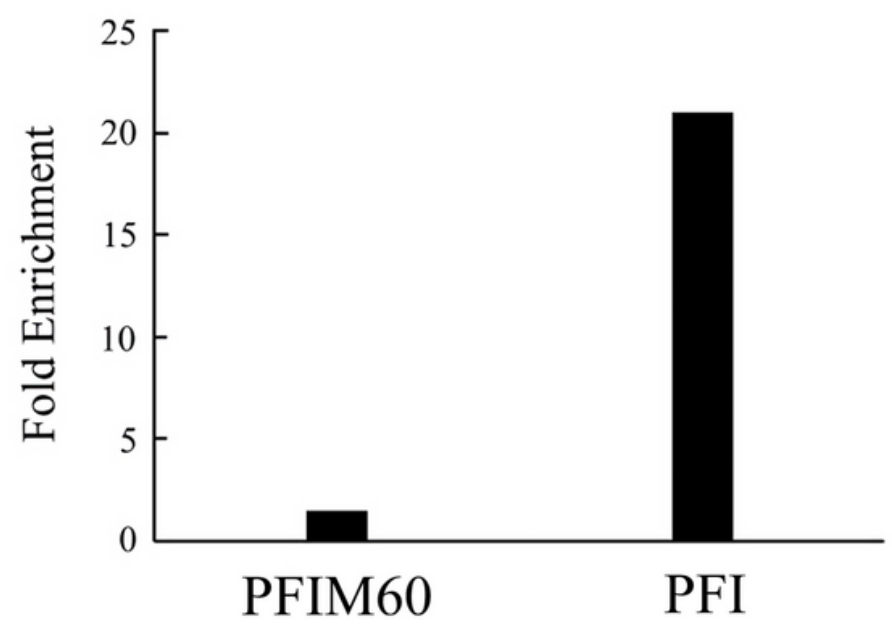

CLV2

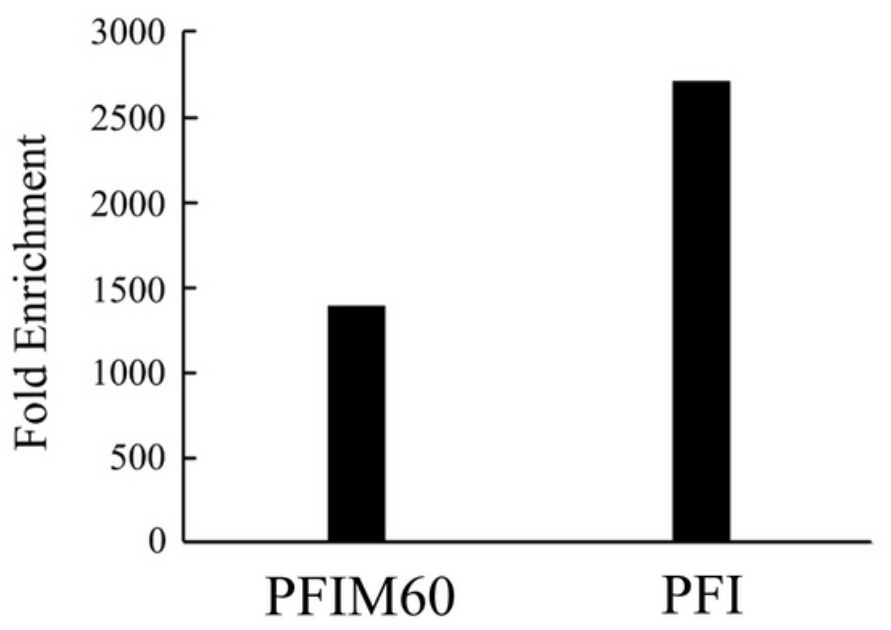

Figure 10

$\mathrm{m}^{6} \mathrm{~A}$ MeRIP-qRT-PCR verification

a b 


\section{Figure 11}

Morphological changes of $P$. fortunei seedling infected with phytoplasma. (a), phytoplasma-infected P. fortunei seedlingThe diseased seedlings have obvious symptoms of witches' broom. (b), $60 \mathrm{mg} \cdot \mathrm{L}-1 \mathrm{MMS}$ treated seedling.

\section{Supplementary Files}

This is a list of supplementary files associated with this preprint. Click to download.

- SupplementalDataFigureS1.pdf

- SupplementalDataFigureS2.pdf

- SupplementalDataTables1.xlsx

- SupplementalDataTableS2.xIsx

- SupplementalDataTableS3.xlsx

- SupplementalDataTableS4.xIsx

- SupplementalDataTableS5.xIsx

- SupplementalDataTableS6.xlsx 